\title{
CONTRIBUIÇÃO DOS CONSTITUINTES DA FRAÇÃO ARGILA DE SOLOS SUBTROPICAIS À ÁREA SUPERFICIAL ESPECÍFICA E À CAPACIDADE DE TROCA CATIÔNICA ${ }^{(1)}$
}

\author{
Ivan Granemann de Souza Junior ${ }^{(2)}$, Antonio Carlos Saraiva da \\ Costa $^{(3)}$, José Alexandre Sambatti ${ }^{(2)}$, Wilson Sacchi Peternele ${ }^{(2)}$, \\ Cássio Antonio Tormena ${ }^{(3)}$, Célia Regina Montes $^{(4)}$ \& Celso Augusto \\ Clemente $^{(4)}$
}

\begin{abstract}
RESUMO
A área superficial específica (ASE) está relacionada com diversas propriedades que definem o comportamento físico-químico dos solos. Neste trabalho, foi estudada a fração argila de 23 amostras de solos desenvolvidos a partir de diferentes materiais de origem, encontrados na região Sul do Brasil, a fim de estabelecer a contribuição dos principais constituintes para a ASE e a capacidade de troca de cátions efetiva (CTCe). Foram identificados os minerais por difratometria de raios $X$ (DRX); quantificados por análise termogravimétrica (ATG); determinados os valores de CTCe e de ASEt (total), pelo método do etilenoglicol mono-etil éter (EGME); de ASEe (externa), pelo método BET- $\mathrm{N}_{2}$; e de ASEi, pela diferença dos valores obtidos entre os dois métodos. Essas determinações foram feitas antes e após os procedimentos seqüenciais de dissolução seletiva, que visavam remover: a matéria orgânica (argila-NaOCl); a matéria orgânica e os óxidos de Fe livres (argila $\mathrm{NaOCl}$ + DCB); e a matéria orgânica, os óxidos de Fe livres, a caulinita, a gibbsita e os minerais aluminossilicatados de baixa cristalinidade (argila- $\mathrm{NaOCl}+\mathrm{DCB}+\mathrm{NaOH}$ $5 \mathrm{~mol} \mathrm{~L}^{-1}$ ). Os solos estudados apresentaram grande variação na mineralogia da fração argila; para a maioria deles, a caulinita foi o mineral predominante, seguido
\end{abstract}

\footnotetext{
(1) Parte da Tese de Mestrado do primeiro autor apresentada ao Programa de Pós-Graduação em Agronomia da Universidade Estadual de Maringá. Financiado pelo CNPq e apresentado no XXIX Congresso Brasileiro de Ciência do Solo, em Ribeirão Preto (SP) em julho de 2003. Recebido para publicação em julho de 2006 e aprovado em julho de 2007.

(2) Pós-Graduando em Agronomia, Universidade Estadual de Maringá - UEM. Av. Colombo 5790, CEP $87020-900$ Maringá (PR). E-mails: ivangsjunior@gmail.com; jasambatti@brturbo.com.br; wspeternele@unir.br

(3) Professor do Departamento de Agronomia, UEM. Bolsista do CNPq. E-mails: acscosta@uem.br; catormena@uem.br

(4) Professor do Departamento de Solos e Nutrição de Plantas, Escola Superior de Agricultura "Luiz de Queiroz" - ESALQ/USP. Av. Pádua Dias 11, Caixa Postal 09, CEP 13418-900 Piracicaba (SP). E-mails: crmlauar@usp.br; clemente@esalq.usp.br
} 
dos argilominerais do tipo 2:1 expansíveis ou dos óxidos e hidróxidos de Fe e Al. Entre a ASEe e a CTCe da fração argila-natural não se constatou relação de dependência, devido ao recobrimento da superfície da amostra pela matéria orgânica. $O$ efeito agregante dos óxidos de Fe promoveu diminuição de $21 \%$ da ASEe. Os argilominerais do tipo 2:1 encontram-se em concentrações variando de 3 a $65 \%$ da fração silicatada, contribuindo com valores médios de $1.054 \mathrm{mmol}_{\mathrm{c}} \mathrm{kg}^{-1} \mathrm{e}$ de $202 \mathrm{~m}^{2} \mathrm{~g}^{-1}$ para CTCe e ASEt, respectivamente. A ASEi contribui com $58 \%$ da ASEt na fração argila com remanescentes de argilominerais do tipo 2:1.

Termos de indexação: EGME, BET-N ${ }_{2}$, dissolução seletiva, argilominerais do tipo 1:1 e 2:1, gibbsita, carbono orgânico.

\title{
SUMMARY: CONTRIBUTION OF CLAY FRACTION MINERALS OF SUBTROPICAL SOILS TO THE SPECIFIC SURFACE AREA AND CATION EXCHANGE CAPACITY
}

\begin{abstract}
The specific surface area (SSA) is related to several properties that define the soil physico-chemical behavior. In this research, 23 soil samples developed from different parent materials found in the southern Brazil were used. They were evaluated for the contribution of the main soil constituents to the effective cation exchange capacity (CECe) and SSA. The clay fraction minerals were identified by $X$ ray diffraction $(X R D)$ and quantified by thermal analysis; the CECe, the SSAt (total) by the ethylene glycol monoethyl ether method (EGME), the SSAe (external) by the BET-N $N_{2}$ method, and the ASEi (internal) by the difference of the values obtained with the two methods. The clay fraction samples were determined before and after the following sequential selective dissolution procedures: removal of organic matter (clay- $\mathrm{NaOCl}$ ); removal of organic matter and free iron oxides (clay- $\mathrm{NaOCl}+\mathrm{DCB})$; removal of kaolinite, gibbsite and low cristalinity aluminosilicate minerals (clay- $\mathrm{NaOCl}+\mathrm{DCB}+\mathrm{NaOH} 5 \mathrm{~mol} \mathrm{~L}-1)$. The mineralogy of the clay fraction of the soils varied considerably, as verified by $X$ ray diffraction, thermogravimetric analysis, and SSA and CECe values. For most soils kaolinite is the predominant mineral in the clay fraction, followed by expandable 2:1 clay mineral or iron and aluminum oxihydroxides. SSA and CECe of the natural clay fraction were not correlated due to the occlusion of the clay surface by organic matter. Iron oxide aggregate effects reduced SSAe by $21 \%$. For the studied samples, the 2:1 clay minerals were present in concentrations varying from 3 to $65 \%$ of the silicate fraction and presented average values of $1.054 \mathrm{mmol}_{\mathrm{c}} \mathrm{kg}^{-1}$ and $202 \mathrm{~m}^{2} \mathrm{~g}^{-}$ ${ }^{1}$ for CECe and SSEt, respectively. SSAi contributed with $58 \%$ of SSAt of the clay fraction, mostly due to 2:1 clay type minerals.
\end{abstract}

Index terms: EGME, BET-N $\mathrm{N}_{2}$, selective dissolution, 1:1 and 2:1 clay minerals, gibbsite and organic carbon.

\section{INTRODUÇÃO}

A maioria dos atributos que definem o comportamento físico-químico dos solos está relacionada com a superfície de reação de seus constituintes orgânicos ou inorgânicos. Esta superfície, por unidade de massa, é conhecida como a área superficial específica total (ASEt, expressa em $\mathrm{m}^{2} \mathrm{~g}^{-1}$ ) (Carter et al., 1986). A ASEt é o somatório das superfícies de exposição interna (ASEi) e externa (ASEe) das partículas (Tiller \& Smith, 1990).

Um dos principais métodos empregados na determinação da ASEt baseia-se na adsorção química de moléculas orgânicas polares, como o etilenoglicol, o etilenoglicol mono-etil éter (EGME) e o glicerol, pela formação de uma camada monomolecular sobre a superfície do material (Carter et al., 1986).

Outro método empregado, com excelente reprodutibilidade, baseia-se na adsorção física de moléculas nãopolares. Neste caso, o método mais comumente adotado emprega a molécula de $\mathrm{N}_{2}$, que é adsorvida à superfície externa da partícula em baixa temperatura $\left(-196^{\circ} \mathrm{C}\right)$, obtendo-se como resultado a ASEe por meio de uma isoterma de adsorção, conforme a teoria de BrunauerEmmett-Teller (BET) (Brunauer et al., 1938).

No solo, a magnitude da ASEt depende principalmente da textura e da mineralogia da fração argila, afetando, por conseqüencia, a capacidade de troca 
catiônica-CTC (Curtin \& Smillie, 1976; Churchman \& Burke, 1991), a capacidade de troca aniônica (Sambatti et al., 2002), a retenção de água em elevados potenciais e a dinâmica de solutos, poluentes e biocidas (Carter et al., 1986; Churchman \& Burke, 1991; Petersen et al., 1996). Portanto, o conhecimento dos valores de ASE das partículas constitui uma ferramenta de fundamental importância na compreensão dos fenômenos de superfície.

A fração argila dos solos tropicais e subtropicais é dominada por minerais, como a caulinita, os sesquióxidos de $\mathrm{Fe}$ e $\mathrm{Al}$, os minerais de argila expansivos do tipo 2:1, a ilita e os óxidos de Ti, como o rutilo e o anatásio (Schwertmann \& Herbillon, 1992; Fontes et al., 2001).

A caulinita, em termos quantitativos, é o principal componente da fração argila da maioria dos solos tropicais e subtropicais e apresenta ASEt predominantemente externa, variando de 5 a $40 \mathrm{~m}^{2} \mathrm{~g}^{-1}$, correlacionando-se positivamente com sua CTC (Dixon, 1989).

Os óxidos de Fe na fração argila dos solos, por terem reduzido tamanho de partícula, apresentam elevados valores de ASEe, que são aumentados por imperfeições na estrutura cristalina dos minerais (Borggaard, 1983; Sambatti et al., 2002). Nesses casos, são encontrados valores de ASEe superiores a $1.000 \mathrm{~m}^{2} \mathrm{~g}^{-1}$ para os óxidos de Fe pobremente cristalinos (Borggaard, 1983).

No caso dos argilominerais expansíveis do tipo 2:1, são observados elevados valores de ASEt devido à expansão desses minerais e à exposição da ASEi nas entrecamadas (Carter et al., 1986; Borchardt, 1989). Entre esses minerais, as esmectitas apresentam elevada ASEe, oriunda do seu reduzido tamanho de partícula, mas a ASEi constitui a maior proporção da ASEt, sendo encontrados valores superiores a $800 \mathrm{~m}^{2} \mathrm{~g}^{-1}$ (Borchardt, 1989).

Para os colóides orgânicos, diversos estudos apontam valores extremamente elevados de ASEt, acima de $700 \mathrm{~m}^{2} \mathrm{~g}^{-1}$, porém contestados em outros estudos. Alguns autores (Chiou et al., 1990; Pennell et al., 1995) atribuem os elevados valores de ASEt obtidos para os colóides orgânicos a uma superestimativa na determinação, devido à adsorção química da molécula empregada.

A avaliação da ASE para explicação de outros atributos do solo e materiais tem sido amplamente utilizada (Grohmann, 1977; Churchman \& Burke, 1991; Petersen et al., 1996; Rolim Neto et al., 2004). Petersen et al. (1996) encontraram correlações significativas e positivas entre a ASE, o conteúdo de argila e a quantidade de água retida em amostras quando submetidas a elevados potenciais. Ainda, Curtin \& Smille (1976) afirmam que a ASE é uma propriedade útil na predição da CTC do solo. De modo semelhante, Grohmann (1977), Tiller \& Smith (1990), Petersen et al. (1996) e Kahle et al. (2002) encontraram correlação positiva entre a CTC e a ASEt ou a retenção de EGME (Churchman \& Burke, 1991). Trabalhos recentes (Kaiser \& Guggenberger, 2003; Kahle et al., 2004) mostram estreitas correlações positiva entre a ASE e a adsorção de C orgânico dissolvido em amostras minerais.

Para solos da região Sul do Brasil, existem poucos trabalhos que avaliam as relações entre a CTCe e os diferentes valores de ASE com a mineralogia da fração argila.

Os objetivos do presente trabalho foram: estudar a mineralogia da fração argila dos horizontes A, B ou C de solos da bacia do rio Paraná; avaliar as relações entre os diferentes valores de ASE e a CTCe após diferentes tratamentos seqüenciais de dissolução seletiva; e avaliar a contribuição dos colóides orgânicos e inorgânicos constituintes da fração argila na CTCe e na ASE (total, externa e interna).

\section{MATERIAL E MÉTODOS}

\section{Solos}

Foram coletadas amostras de 23 horizontes superficial (A) e subsuperficial (B ou C) de 19 perfis de solos da bacia do rio Paraná, nos Estados do Paraná, Santa Catarina e Rio Grande do Sul (Quadro 1). No Paraná, as amostras foram coletadas numa toposseqüência de solos derivados de basalto. Os solos de Santa Catarina e do Rio Grande do Sul foram amostrados durante a VI Reunião de Classificação e Correlação de Solos, realizada na região Sul, promovido pela Embrapa-Solos, universidades e outros institutos de pesquisa das regiões Sul e Sudeste. As amostras foram secas ao ar, destorroadas e passadas em peneira de $2 \mathrm{~mm}$ de abertura de malha, obtendo-se assim a terra fina seca ao ar (TFSA).

\section{Atributos químicos e análise granulométrica da TFSA}

Os métodos utilizados na caracterização física e química dos solos estão descritos em Embrapa (1997). As análises foram realizadas no Laboratório de Química e Mineralogia do Solo (LQMS), do Departamento de Agronomia da Universidade Estadual de Maringá.

A análise granulométrica foi feita pelo método da pipeta, utilizando-se $\mathrm{NaOH} 0,01 \mathrm{~mol} \mathrm{~L}^{-1}$ como agente dispersante, sob agitação mecânica. $\mathrm{O}$ teor de carbono orgânico total (COT) foi determinado pela oxidação da matéria orgânica do solo via úmida (método WalkleyBlack). Ca e Mg trocáveis foram extraídos com KCl $1 \mathrm{~mol} \mathrm{~L}^{-1} \mathrm{e}$ determinados por espectrofotometria de absorção atômica. O teor de K trocável foi determinado por fotometria de emissão de chama, após extração com Mehlich-1. A acidez potencial $(\mathrm{H}+\mathrm{Al})$ foi determinada após extração com acetato de cálcio (1 mol L-1 tamponado a pH 7 e titulado com solução 
Quadro 1. Classificação, horizonte amostrado, localidade e material de origem e condição de drenagem dos solos estudados

\begin{tabular}{|c|c|c|c|c|c|}
\hline Perfil & Classe $^{(1)}$ & Horizonte & Localidade & Material de origem & $\begin{array}{c}\text { Condição de } \\
\text { drenagem }\end{array}$ \\
\hline 1 & Latossolo Vermelho (LV1) & $\mathrm{A}$ & Maringá - PR & Basalto & Excessiva \\
\hline 1 & Latossolo Vermelho (LV1) & $\mathrm{B}$ & Maringá - PR & Basalto & Excessiva \\
\hline 11 & Latossolo (L1) & $\mathrm{A}$ & Tupanciretã - RS & Arenito & Excessiva \\
\hline 12 & Latossolo Vermelho (LV3) & A & Ibirubá - RS & Basalto & Excessiva \\
\hline 13 & Latossolo Bruno (LB1) & $\mathrm{A}$ & Muitos Capões - RS & Basalto & Excessiva \\
\hline 14 & Latossolo Bruno (LB2) & A & Vacaria - RS & Basalto & Excessiva \\
\hline 18 & Latossolo Vermelho (LV4) & $\mathrm{A}$ & Canoinhas - SC & Folhelhos síltico-argilosos & Excessiva \\
\hline 19 & Argissolo (P1) & A & Otacílio Costa - SC & Siltitos & Excessiva \\
\hline 2 & Nitossolo Vermelho (NV1) & $\mathrm{A}$ & Maringá - PR & Basalto & Perfeita \\
\hline 2 & Nitossolo Vermelho (NV1) & $\mathrm{B}$ & Maringá - PR & Basalto & Perfeita \\
\hline 17 & Nitossolo (N1) & $\mathrm{A}$ & Lebon Régis - SC & Basalto & Perfeita \\
\hline 3 & Chernossolo Argilúvico (MT1) & $\mathrm{A}$ & Maringá - PR & Basalto & Moderada \\
\hline 3 & Chernossolo Argilúvico (MT1) & $\mathrm{B}$ & Maringá - PR & Basalto & Moderada \\
\hline 6 & Argissolo (P2) & A & Canguçú - RS & Migmatito & Moderada \\
\hline 15 & Cambissolo Háplico (CX1) & $\mathrm{A}$ & Pelotas - RS & Riodacito & Moderada \\
\hline 16 & Nitossolo Háplico (NX1) & $\mathrm{A}$ & Lages - SC & Basalto & Moderada \\
\hline 4 & Vertissolo Hidromórfico (VG1) & $\mathrm{A}$ & Maringá - PR & Basalto & Imperfeita \\
\hline 4 & Vertissolo Hidromórfico (VG1) & $\mathrm{C}$ & Maringá - PR & Basalto & Imperfeita \\
\hline 5 & Plintossolo Háplico (FX1) & $\mathrm{A}$ & Camaquã - RS & Sedimentos arenosos & Imperfeita \\
\hline 7 & Argissolo Amarelo (PA1) & A & Pinheiro Machado - RS & Migmatito & Imperfeita \\
\hline 8 & Chernossolo Ebânico (ME1) & $\mathrm{A}$ & Bagé - RS & Folhelhos sílticos & Imperfeita \\
\hline 9 & Luvissolo Hipocrômico (TP1) & $\mathrm{A}$ & Bagé - RS & Folhelhos & Imperfeita \\
\hline 10 & Luvissolo Hipocrômico (TP2) & A & Formigueiro - RS & Siltitos areno-argilosos & Imperfeita \\
\hline
\end{tabular}

(1) Classificação do solo até o segundo nível categórico, conforme Embrapa (1999), separados de acordo com a condição de drenagem do perfil.

de $\mathrm{NaOH}$ 0,025 mol L-1), na presença de fenolftaleína como indicador. A capacidade de troca catiônica a $\mathrm{pH}$ $7\left(\mathrm{CTC}_{7}\right)$ foi calculada pelo somatório dos teores de $\mathrm{Ca}^{2+}+\mathrm{Mg}^{2+}+\mathrm{K}^{+}+(\mathrm{H}+\mathrm{Al})$.

\section{Caracterização da fração argila}

Para caracterização da fração argila, fracionou-se o solo, utilizando $50 \mathrm{~g}$ de cada amostra, que foram colocados em frascos de agitação com capacidade de $1 \mathrm{~L}$. Em seguida, adicionou-se $\mathrm{NaOH} 0,02 \mathrm{~mol} \mathrm{~L}^{-1}$ como agente dispersante, mantendo as amostras durante oito horas sob agitação mecânica. Após esse período, para que houvesse completa separação das frações granulométricas, as amostras foram submetidas à dispersão ultra-sônica durante cinco minutos em um equipamento Sonopuls, operado na potência de $20 \mathrm{~W}$. Separaram-se a fração areia por tamisamento (retido em peneira com malha de $0,053 \mathrm{~mm}$ ) e a fração argila por sifonamento após sedimentação da fração silte, conforme lei de Stokes.
Após separação, a fração argila foi floculada com $\mathrm{MgCl}_{2}$ $1 \mathrm{~mol} \mathrm{~L}^{-1}$, sendo o excesso de $\mathrm{Mg}^{2+} \mathrm{e} \mathrm{Cl}^{-}$removido por lavagens sucessivas com água deionizada. Em seguida, o material foi congelado em $\mathrm{N}_{2}$ líquido e liofilizado (Perrott, 1977).

Depois de liofilizada, separou-se uma porção da fração argila (argila-natural) para obtenção da fração argila livre de matéria orgânica. A remoção da matéria orgânica foi feita com hipoclorito de sódio com $6 \%$ de $\mathrm{Cl}$ ativo, $\mathrm{pH}$ ajustado a 9,5 (Moore \& Reynolds, 1997), aquecido a $90^{\circ} \mathrm{C}$ durante uma hora sob agitação periódica. Após esse período, o material foi centrifugado; descartou-se o sobrenadante e repetiu-se o procedimento por mais duas vezes. O material resultante (argila$\mathrm{NaOCl}$ ) foi saturado por $\mathrm{Mg}^{2+}$, lavado repetidas vezes com água deionizada e liofilizado.

O teor dos óxidos de $\mathrm{Fe}$ livres foi determinado numa fração da argila-NaOCl, após extração com ditionitocitrato-bicarbonato de sódio (DCB) (Mehra \& Jackson, 1960). Os teores de $\mathrm{Fe} \mathrm{e} \mathrm{Al}$ associados às formas de 
baixo grau de cristalinidade na fração argila-natural foram determinados após extração com oxalato ácido de amônio (OAA) (Camargo et al., 1986). Os teores de $\mathrm{Fe}$ e Al nos extratos de DCB e OAA foram determinados por espectrofotometria de absorção atômica.

As amostras desferrificadas e livres de matéria orgânica (argila-DCB), após serem saturadas com $\mathrm{Mg}^{2+} \mathrm{e}$ liofilizadas, foram submetidas à análise termogravimétrica (TGA) para quantificação dos teores de gibbsita e caulinita, com base na perda de massa associada aos picos endotérmicos, resultantes da desidroxilação destas espécies minerais, nas temperaturas de aproximadamente 250 e $500{ }^{\circ} \mathrm{C}$, respectivamente (Karathanasis \& Harris, 1994). Os termogramas foram obtidos num equipamento Shimadzu, TA-50, operando em atmosfera de $\mathrm{N}_{2}$, num fluxo de $20 \mathrm{~mL} \mathrm{~min}{ }^{-1} \mathrm{e}$ taxa de aquecimento de $20^{\circ} \mathrm{C}$ $\min ^{-1}$. Os teores de argilominerais do tipo 2:1 na fração argila-DCB foram calculados considerando-os complementares aos teores de caulinita e gibbsita (Costa et al., 2004).

A dissolução da caulinita e da gibbsita foi realizada na fração argila-DCB, utilizando-se $\mathrm{NaOH} 5 \mathrm{~mol} \mathrm{~L}^{-1}$ a quente (Kämpf \& Schwertmann, 1982), obtendo-se assim a fração argila desferrificada concentrada de argilominerais do tipo 2:1 (Costa et al., 1995).

A composição mineralógica das frações argila desferrificada (argila-DCB) e concentrada de argilominerais do tipo 2:1 (argila- $\mathrm{DCB}+\mathrm{NaOH}$ $5 \mathrm{~mol} \mathrm{~L}^{-1}$ ) foi avaliada por difratometria de raios $\mathrm{X}$ (DRX) em lâminas orientadas dos materiais saturados com $\mathrm{Mg}^{2+}$ sem ou com glicolação e $\mathrm{K}^{+}$, não aquecidas e após aquecimento a $550^{\circ} \mathrm{C}$ (Moore \& Reynolds, 1997). As análises de DRX foram feitas no NUPEGELESALQ/USP. Os difratogramas foram obtidos entre 3 e $30^{\circ} 2 \theta$, em intervalos de $0,05^{\circ} 2 \theta$, com tempo de contagem de $2 \mathrm{~s}$, num equipamento Philips PW, operando a $40 \mathrm{~mA} \mathrm{e} 40 \mathrm{kV}$, utilizando radiação $\mathrm{CuK \alpha}$ e filtro de $\mathrm{Ni}$.

A CTCe dos materiais obtidos após os diferentes tratamentos de dissolução seletiva foi determinada por um processo de extração seqüencial múltipla, num extrator mecânico a vácuo, conforme método descrito por Jaynes \& Bigham (1986), utilizando-se $\mathrm{Ca}^{2+}$ como cátion-índice e $\mathrm{KCl}$ como solução extratora.

A área superficial específica total (ASEt) foi determinada gravimetricamente, pela retenção do etilenoglicol mono-etil éter (EGME), conforme método descrito pela Embrapa (1997). A área superficial específica externa (ASEe) foi determinada pelo método BET-N ${ }_{2}$ num equipamento Quantachrome, Quantasorb Surface Área Analyser, utilizando uma mistura $30 / 70$ dos gases $\mathrm{N}_{2} / \mathrm{He}$. A área superficial específica interna (ASEi) foi calculada pela diferença entre a ASEt e a ASEe.

Foram feitas análises de regressão linear simples entre os valores de ASE (ASEt, ASEe e ASEi) e os valores de CTCe para os materiais após os diferentes procedimentos de dissolução seletiva e análise de correlação entre a concentração das espécies minerais na fração argila e os valores de ASEe das frações, utilizando-se o programa estatístico SAS (SAS, 1999).

\section{RESULTADOS E DISCUSSÃO}

\section{Caracterização da TFSA}

No conjunto das amostras estudadas (Quadro 1), os solos desenvolvidos a partir de rochas vulcânicas básicas (basalto), ácidas (riodacito) e das sedimentares argilosas (folhelhos) e dos siltitos apresentaram textura argilosa. As demais rochas sedimentares e metamórficas (migmatitos) desenvolveram solos de textura média a arenosa.

O teor médio de argila encontrado nos solos foi de $493 \mathrm{~g} \mathrm{~kg}^{-1}$, variando de $100 \mathrm{~g} \mathrm{~kg}^{-1}$ para o Plintossolo Háplico de Camaquã-RS (perfil 5, FX1) a $850 \mathrm{~g} \mathrm{~kg}^{-1}$ para o Latossolo Vermelho de Maringá-PR (perfil 1, LV1), formados, respectivamente, a partir de sedimentos arenosos e de basalto (Quadro 2).

O teor médio de COT na TFSA foi de $19,3 \mathrm{~g} \mathrm{~kg}^{-1}$, variando de 7,5 $\mathrm{g} \mathrm{kg}^{-1}$ para o Latossolo de TupanciretãRS (perfil 11, L1) a $39,3 \mathrm{~g} \mathrm{~kg}^{-1}$ para o Cambissolo Háplico de Pelotas-RS (perfil 15, CX1). As condições de drenagem não influenciaram a quantidade de COT dos solos.

A CTC 7 da TFSA variou de $54 \mathrm{mmol}_{\mathrm{c}} \mathrm{dm}^{-3}$ no Plintossolo Háplico de Camaquã-RS (perfil 5, FX1) a $420 \mathrm{mmol}_{\mathrm{c}} \mathrm{dm}^{-3}$ no Vertissolo Hidromórfico de Maringá-PR (perfil 4, VG1), com valor médio de $169 \mathrm{mmol}_{\mathrm{c}} \mathrm{dm}^{-3}$. Para a fração argila, os valores de CTC variaram de 103 a $792 \mathrm{mmol}_{\mathrm{c}} \mathrm{dm}^{-3}$ para o Latossolo Vermelho de Maringá-PR (perfil 1, LV1) e para o Chernossolo Ebânico de Bagé-RS (perfil 8, ME1), o valor médio encontrado foi de $413 \mathrm{mmol}_{\mathrm{c}} \mathrm{dm}^{-3}$, o que demonstra o predomínio de solos com argila de atividade alta.

Os valores de $\mathrm{CTC}_{7}$ não apresentaram relação significativa com os teores de COT e argila dos solos, demonstrando ampla variação nas características químicas e mineralógicas dos solos, produto da variabilidade dos processos pedogenéticos envolvidos.

\section{Mineralogia da fração argila}

A ampla variação de materiais de origem, associada ao ambiente de formação e intensidade de intemperismo químico nas diferentes classes de solos, foi responsável pela variação na mineralogia da fração argila dos solos estudados (Quadro 2).

Nos ambientes com problemas de drenagem constataram-se as maiores proporções relativas de formas pobremente cristalinas dos óxidos de $\mathrm{Fe}$, em relação às formas livres. A relação entre os teores de 
Quadro 2. Perfil, classe, horizonte, teor de argila, carbono orgânico total e CTC 7 da TFSA, teores de Fe e Al extraídos com ditionito-citrato-bicarbonato de sódio (DCB) e oxalato ácido de amônio (OAA) na fração argila e de caulinita, gibbsita e argilominerais do tipo 2:1 na argila desferrificada

\begin{tabular}{|c|c|c|c|c|c|c|c|c|c|c|c|c|c|c|}
\hline \multirow{2}{*}{ Perfil } & \multirow{2}{*}{ Classe } & \multirow{2}{*}{ Hor. } & \multicolumn{3}{|c|}{ TFSA } & \multicolumn{4}{|c|}{ Fração argila } & \multirow{2}{*}{ Fed/Feo } & \multirow{2}{*}{ Ald/Alo } & \multirow{2}{*}{$\mathrm{Cau}$} & \multirow{2}{*}{ Gib } & \multirow{2}{*}{$2: 1$} \\
\hline & & & Argila & COT & $\mathrm{CTC}_{7}$ & Fed & Feo & Ald & Alo & & & & & \\
\hline & & & \multicolumn{2}{|c|}{$-\mathrm{g} \mathrm{kg}^{-1}-$} & $\mathrm{mmol}_{\mathrm{c}} \mathrm{kg}^{-1}$ & \multicolumn{4}{|c|}{$\%$} & & & 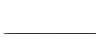 & $\%$ & - \\
\hline 1 & LV1 & A & 710 & 20,2 & 101 & 13,63 & 0,81 & 0,94 & 0,33 & 17 & 3 & 69,83 & 4,17 & 4,8 \\
\hline 1 & LV1 & B & 850 & 11,1 & 87 & 14,57 & 0,71 & 1,08 & 0,38 & 21 & 3 & 69,99 & 4,05 & 3,1 \\
\hline 11 & $\mathrm{~L} 1$ & A & 200 & 7,5 & 65 & 4,03 & 0,39 & 1,07 & 0,54 & 10 & 2 & 76,17 & 0 & 16,0 \\
\hline 12 & LV3 & A & 570 & 19,0 & 145 & 11,18 & 0,69 & 0,73 & 0,37 & 16 & 2 & 71,77 & 1,20 & 9,7 \\
\hline 13 & LB1 & A & 670 & 31,0 & 195 & 11,29 & 0,42 & 1,91 & 0,49 & 27 & 4 & 66,4 & 1,15 & 12,7 \\
\hline 14 & LB2 & A & 670 & 24,2 & 169 & 10,55 & 0,37 & 2,44 & 0,45 & 29 & 5 & 64,39 & 1,68 & 14,3 \\
\hline 18 & LV4 & A & 540 & 22,5 & 134 & 7,79 & 0,41 & 2,95 & 0,75 & 19 & 4 & 48,84 & 22,78 & 11,7 \\
\hline 19 & $\mathrm{P} 1$ & A & 610 & 28,6 & 247 & 6,10 & 0,40 & 1,43 & 0,48 & 15 & 3 & 71,90 & 0 & 16,7 \\
\hline Média & & & 603 & 20,5 & 143 & 9,89 & 0,53 & 1,57 & 0,47 & 19,2 & 3,3 & 67,41 & 4,38 & 11,1 \\
\hline 2 & NV1 & A & 690 & 23,1 & 116 & 14,08 & 0,82 & 1,08 & 0,32 & 17 & 3 & 65,92 & 2,67 & 9,2 \\
\hline 2 & NV1 & B & 770 & 13,2 & 147 & 12,67 & 0,81 & 0,99 & 0,37 & 16 & 3 & 66,95 & 2 & 11,1 \\
\hline 17 & N1 & A & 660 & 22,8 & 127 & 9,22 & 0,38 & 1,72 & 0,37 & 31 & 5 & 72,82 & 0 & 10,8 \\
\hline Média & & & 707 & 19,7 & 130 & 11,99 & 0,67 & 1,26 & 0,35 & 19,0 & 3,7 & 68,56 & 1,56 & 10,4 \\
\hline 3 & MT1 & A & 410 & 23,9 & 272 & 11,46 & 1,13 & 0,96 & 0,28 & 10 & 3 & 63,7 & 2,40 & 15,7 \\
\hline 3 & MT1 & B & 600 & 16,7 & 230 & 13,17 & 1,15 & 1,21 & 0,31 & 11 & 4 & 37,47 & 0 & 41,4 \\
\hline 6 & $\mathrm{P} 2$ & A & 250 & 16,5 & 137 & 1,61 & 0,41 & 0,69 & 0,49 & 4 & 1 & 60,65 & 0 & 35,7 \\
\hline 15 & CX1 & A & 520 & 39,3 & 209 & 3,26 & 0,27 & 1,39 & 0,61 & 12 & 2 & 69,02 & 0 & 23,7 \\
\hline 16 & NX1 & A & 490 & 26,6 & 145 & 9,64 & 0,28 & 2,44 & 0,39 & 34 & 6 & 69,30 & 0 & 12,3 \\
\hline Média & & & 454 & 24,6 & 199 & 7,83 & 0,65 & 1,338 & 0,416 & 14,4 & 3,2 & 60,03 & 0,48 & 25,8 \\
\hline 4 & $\mathrm{VG} 1$ & $\mathrm{~A}$ & 580 & 16,8 & 420 & 5,61 & 0,74 & 0,4 & 0,16 & 8 & 3 & 62,42 & 0 & 22,8 \\
\hline 4 & $\mathrm{VG} 1$ & $\mathrm{C}$ & 580 & 10,1 & 397 & 1,44 & 0,85 & 0,35 & 0,16 & 2 & 2 & 74,87 & 0 & 22,4 \\
\hline 5 & FX1 & A & 100 & 8,2 & 54 & 0,81 & 0,17 & 0,60 & 0,49 & 5 & 1 & 55,58 & 0 & 42,1 \\
\hline 7 & PA1 & A & 130 & 13,5 & 84 & 1,75 & 0,54 & 0,61 & 0,42 & 3 & 1 & 61,48 & 0 & 34,9 \\
\hline 8 & ME1 & A & 240 & 22,8 & 190 & 0,68 & 0,39 & 0,33 & 0,31 & 2 & 1 & 41,61 & 0 & 56,8 \\
\hline 9 & $\mathrm{TP} 1$ & $\mathrm{~A}$ & 160 & 15,0 & 102 & 2,25 & 0,38 & 0,72 & 0,54 & 6 & 1 & 63,41 & 0 & 32,0 \\
\hline 10 & TP2 & A & 160 & 11,3 & 124 & 0,72 & 0,39 & 0,60 & 0,35 & 2 & 2 & 32,79 & 0 & 65,0 \\
\hline Média & & & 279 & 14,0 & 196 & 1,89 & 0,49 & 0,52 & 0,35 & 3,8 & 1,6 & 56,02 & 0,00 & 39,4 \\
\hline
\end{tabular}

COT: carbono orgânico total; $\mathrm{CTC}_{7}$ : soma de bases + $(\mathrm{H}+\mathrm{Al})$; Fed e Ald: teores de Fe e Al extraíveis com DCB; Feo e Alo: teores de Fe e Al extraíveis com OAA; Cau: caulinita e Gib: gibbsita, determinados por análise termogravimétrica, 2:1 (residual): obtido pela subtração da quantidade total de caulinita e gibbsita na amostra, após constatação desses minerais por difratometria de raios $\mathrm{X}$.

Fed/Feo para a fração argila livre de matéria orgânica foi de 19,2 para os solos com drenagem excessiva, 19,0 para os solos com drenagem perfeita, 14,4 para os solos com drenagem moderada e 3,8 para os solos com drenagem imperfeita. Na maioria desses solos, os óxidos de Fe na fração argila eram representados por associações com variadas proporções de hematita, goethita e maghemita (Costa et al., 1999).
O avançado estádio de intemperismo promovido pelo clima subtropical da região Sul do Brasil faz com que a caulinita seja o mineral dominante na fração argila desferrificada da maioria dos solos estudados, exceto para os Chernossolos (MT1, horizonte C, e ME1, horizonte A) de Maringá-PR e Bagé-RS, respectivamente, e para o Luvissolo (TP2, horizonte A) de Formigueiro$\mathrm{RS}$, pois estes solos ocorrem em posições do relevo que 
favorecem a manutenção de um ambiente mais rico em sílica e a diagênese de minerais silicatados de maior atividade (Moniz et al., 1982). Dados semelhantes foram obtidos por Costa et al. (1995) para solos desenvolvidos a partir de rochas eruptivas básicas e intermediárias do Estado do Paraná.

Os minerais de argila do tipo $2: 1$ constituem a segunda maior concentração em 11 das 23 amostras estudadas, aumentando nos solos menos intemperizados ou com drenagem impedida (Quadro 2). O teor médio variou de $10,4 \%$ para os solos com drenagem perfeita a $39,4 \%$ para aqueles com drenagem imperfeita.

Em menores proporções, associada aos solos em estádios mais avançados de intemperismo, a gibbsita esteve presente em nove das 23 amostras de solos estudados. No Latossolo Vermelho de Canoinhas-SC, a gibbsita foi a segunda espécie mineral na fração argila deste solo, o qual se encontra no estádio mais avançado de intemperismo entre as amostras utilizadas. A composição mineralógica dos solos está de acordo com as afirmações de Schwertmann \& Herbillon (1992) e de Fontes et al. (2001) para a mineralogia da fração argila dos solos tropicais.

\section{Distribuição dos constituintes da fração argila}

Os métodos de extração seqüencial empregados para avaliação da contribuição dos diferentes componentes da fração argila dos solos foram eficientes na remoção/concentração dessas fases, conforme constatado por DRX do resíduo após as extrações com $\mathrm{DCB}$ e com DCB + NaOH $5 \mathrm{~mol} \mathrm{~L}^{-1}$ (Figura 1). Observou-se que, além dos argilominerais do tipo 2:1, outros minerais mais resistentes ao intemperismo, como o quartzo e o anatásio, estavam presentes na fração argila desses solos e aparentemente não foram afetados pelos procedimentos seqüenciais de dissolução seletiva. No entanto, esses minerais ocorrem em pequenos teores, de modo que sua existência torna-se evidente somente após remoção dos constituintes em maiores proporções (Kämpf \& Schwertmann, 1982).

Após os tratamentos de dissolução seletiva com $\mathrm{DCB}+\mathrm{NaOH} 5 \mathrm{~mol} \mathrm{~L}^{-1}$, em todos os solos estudados foi possível aumentar a proporção dos argilominerais do tipo $2: 1$, principalmente esmectitas, que apresentavam espaçamento basal de aproximadamente $15 \AA$ quando saturadas com $\mathrm{Mg}^{2+}$ e entre 17 e $18 \AA$ após glicoladas (Barnhisel \& Bertsch, 1989). Quando saturadas com $\mathrm{K}^{+}$e submetidas aos tratamentos térmicos $\left(350 \mathrm{e} 550^{\circ} \mathrm{C}\right)$, verificou-se o colapso e redução do espaçamento basal para 10-11 Å, coincidente com o reflexo da ilita, nas amostras 11 e 14, que manteve seu espaçamento basal inalterado pelos tratamentos térmicos e de glicolagem. Esses argilominerais são responsáveis, em grande parte, pela atividade da argila (Embrapa, 1999), representada pelos valores de $\mathrm{CTC}_{7}$ (Quadro 2)
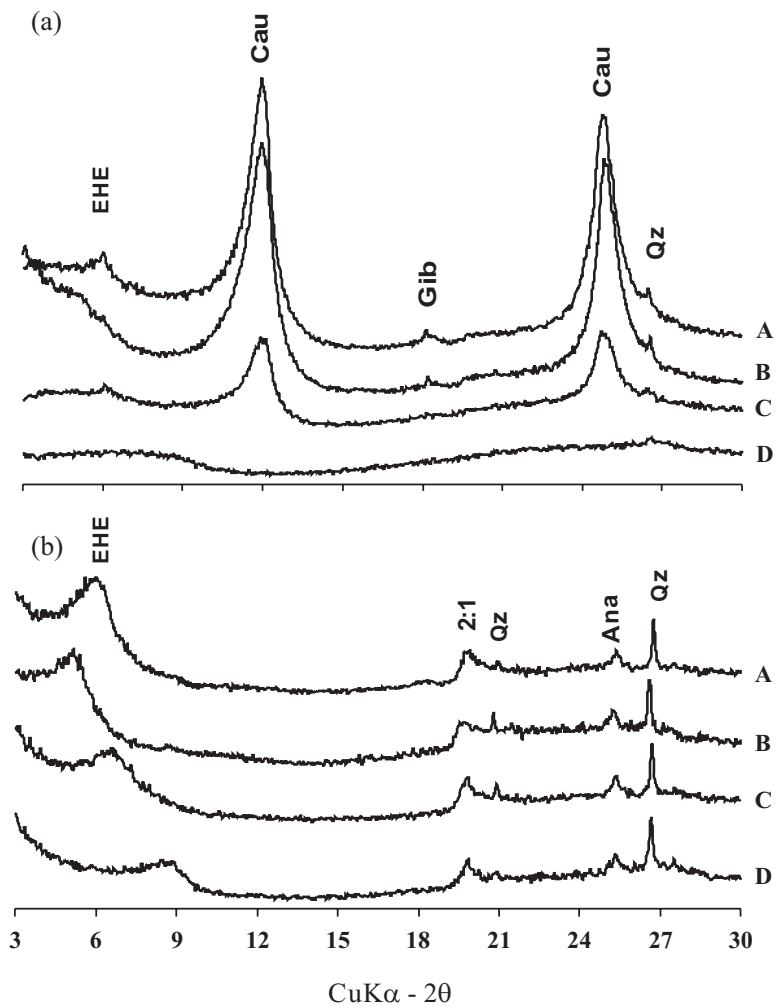

Figura 1. Difratogramas de raios $X$ da fração argila orientada do horizonte A do Chernossolo Argilúvico (perfil 3, MT1), mostrando a variação na mineralogia promovida pelos tratamentos com DCB (a) e com DCB+NaOH $5 \mathrm{~mol} \mathrm{~L}^{-1}$ fervendo (b). (A) amostra saturada com Mg; (B) Mg-glicolada; (C) saturada com K a $25{ }^{\circ} \mathrm{C}$; (D) $\mathrm{K}-550{ }^{\circ} \mathrm{C}$. (EHE): esmectita com hidroxi-Al entrecamadas; (Cau): caulinita; (2:1): argilomineral do tipo 2:1 ; (Ana): anatásio; (Qz): quartzo.

A permanência desses minerais em solos tropicais deve-se, provavelmente, à existência de polímeros de $\mathrm{Al}$-entrecamadas denominados VHE ou EHE (Fontes, 1990), que aumentam sua resistência ao processo de intemperismo diante das condições ambientais (Kämpf et al., 1995). Todavia, a presença desses polímeros também é responsável pela diminuição da CTC e da ASEi desses minerais (Barnhisel \& Bertsch, 1989), além de alterar a posição dos reflexos de seus planos de difração de raios X (Moore \& Reynolds, 1997).

\section{CTCe e ASE da fração argila natural}

Entre a ASEe e a CTCe da argila natural não se constatou relação significativa de dependência (Quadro 3). Pennell et al. (1995), Mayer \& Xing (2001) e Kaiser \& Guggenberger (2003) afirmam que a presença de matéria orgânica promove diminuição da ASEe quando determinada pelo método $B E T-\mathrm{N}_{2}$, pelo fato de ela recobrir a superfície das partículas minerais do solo, promovendo sua oclusão, quando exposta ao $\mathrm{N}_{2}$. 
Quadro 3. Equações de regressão e coeficientes de determinação $\left(R^{2}\right)$ entre a $\mathrm{CTC}_{\mathrm{e}}$ da fração argila (y) após os diferentes procedimentos de dissolução seletiva, como variável dependente da ASE (x)

\begin{tabular}{|c|c|c|}
\hline ASE & Equação & $\mathbf{R}^{2}$ \\
\hline \multicolumn{3}{|c|}{ Argila-natural } \\
\hline Externa: BET & $\mathrm{ns}$ & ns \\
\hline Interna: ASEt-ASEe & $\hat{\mathrm{y}}=178,32+2,759^{* * *} \mathrm{x}$ & 0,69 \\
\hline Total: EGME & $\hat{y}=117,04+2,0565^{* *} x$ & 0,47 \\
\hline \multicolumn{3}{|c|}{ Argila- $\mathrm{NaOCl}$} \\
\hline Externa: BET & $\hat{y}=-183,66+5,577^{* *} x$ & 0,32 \\
\hline Interna: ASEt-ASEe & $\hat{y}=139,43+2,801^{* * * x}$ & 0,93 \\
\hline Total: EGME & $\hat{y}=-31,63+2,345^{* * *} \mathrm{x}$ & 0,92 \\
\hline \multicolumn{3}{|c|}{ Argila- $\mathrm{NaOCl}+\mathrm{DCB}$} \\
\hline Externa: BET & $\hat{y}=-28,67+3,076^{* *} x$ & 0,32 \\
\hline Interna: ASEt-ASEe & $\hat{y}=64,22+3,025^{* * *} \mathrm{x}$ & 0,88 \\
\hline Total: EGME & $\hat{y}=-29,93+1,999 * * * x$ & 0,81 \\
\hline \multicolumn{3}{|c|}{ Argila- $\mathrm{NaOCl}+\mathrm{DCB}+\mathrm{NaOH} 5$ mol L- 1} \\
\hline Externa: BET & $\hat{y}=-395,24+5,934^{*} x$ & 0,33 \\
\hline Interna: ASEt-ASEe & $\hat{y}=390,95+2,870 * x$ & 0,23 \\
\hline Total: EGME & $\hat{y}=-29,27+3,484^{* * * x}$ & 0,51 \\
\hline
\end{tabular}

***, **, * e ns: Significativos a $0,1,1$ e $5 \%$ e não-significativo a $5 \%$, respectivamente.

A presença de minerais com elevada ASEe, mas com baixa ou ausente CTCe, isto é, gibbsita e os oxihidróxidos de $\mathrm{Fe}$ e $\mathrm{Al}$, tende a promover a dispersão dos dados e, conseqüentemente, a falta de relação linear entre essas variáveis.

Os resultados obtidos para a ASEt explicam apenas $47 \%$ da CTCe $\left(\mathrm{R}^{2}=0,47\right)$ e confirmam a hipótese de Mayer \& Xing (2001), de que a presença da matéria orgânica obstrui o acesso de parte da superfície da amostra ao $\mathrm{N}_{2}$; por isso, subestima a ASEe ou superestima a ASEt, por ser capaz de se complexar quimicamente com o EGME, formando, neste caso, um complexo de esfera interna (Chiou et al., 1990; Pennell et al., 1995).

Se, por um lado, a ASEt é influenciada pelas variações na mineralogia (Churchman \& Burke, 1991) e por haver quimiossorção do EGME pela matéria orgânica, por outro, a ASEe pode ser comprometida em amostras que contêm argilominerais expansíveis do tipo 2:1, por não avaliar sua superfície interna. Dessa forma, a melhor relação encontrada entre CTCe e ASE na fração argila-natural foi com a ASEi $\left(\mathrm{R}^{2}=0,69\right)$ presente somente nos argilominerais do tipo 2:1, mostrando que a superfície interna desses minerais contribui efetivamente com a CTCe.

\section{CTCe e ASE da fração argila livre de matéria orgânica, argila-NaOCl}

Após remoção da matéria orgânica, verificou-se melhor relação $\left(R^{2}=0,32\right)$ entre a ASEe e a CTCe, comparativamente com a obtida para a argila-natural. Em média, a remoção da matéria orgânica promoveu redução de aproximadamente $18 \%$ nos valores de CTCe, porém levou a significativo incremento - em média, $68 \%$ - na ASEe. Comportamento semelhante foi observado por Chiou et al. (1990), Pennell et al. (1995), Mayer \& Xing (2001), Kahle et al. (2002) e Kaiser \& Guggenberger (2003). De acordo com Chiou et al. (1990) e Pennell et al. (1995), a ASEe da matéria orgânica é extremamente baixa $\left(<1 \mathrm{~m}^{2} \mathrm{~g}^{-1}\right)$ e pode promover a diminuição da ASEe pelo recobrimento da superfície da amostra. Esses autores sugerem ainda que maior atenção deva ser dada aos valores de ASEe obtidos em amostras com elevados teores de matéria orgânica.

Entre a ASEt e a CTCe observou-se estreita e positiva relação $\left(R^{2}=0,92\right)$, devido à acessibilidade da molécula do EGME aos diversos sítios de adsorção na fração mineral dos solos sem a interferência da matéria orgânica (Figura 2). A mesma tendência foi verificada entre a CTCe e a ASEi $\left(R^{2}=0,93\right)$, demonstrando a dependência da CTCe com superfície interna, presente unicamente nos argilominerais do tipo 2:1.

\section{CTCe e ASE da fração argila livre de matéria orgânica e dos óxidos de ferro livres}

$\mathrm{Na}$ fração argila desferrificada foi observada relação positiva baixa, mas significativa, entre a CTCe e a ASEe $\left(R^{2}=0,32\right.$ ) (Quadro 3). Esse comportamento se deve a minerais com elevada CTC, porém que não está restrita à superfície interna, como as esmectitas (Borchardt, 1989).

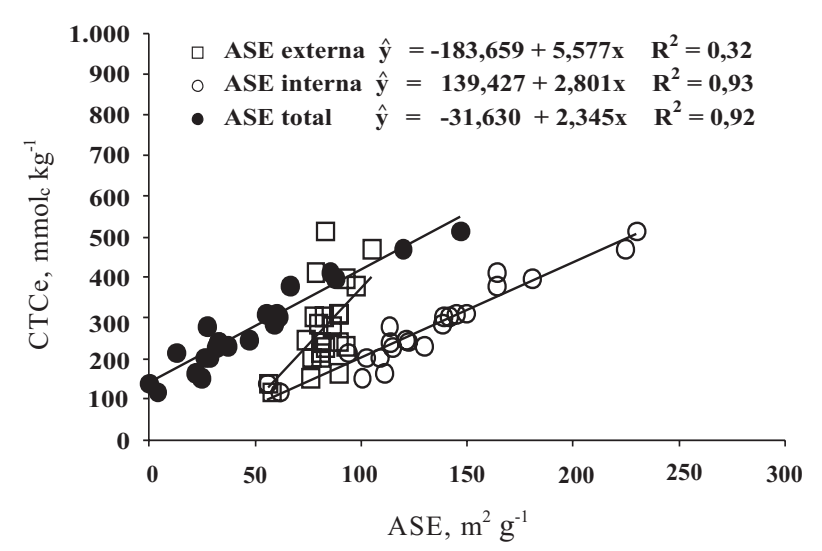

Figura 2. Relações entre os valores de área superficial específica (ASE) e a capacidade de troca catiônica efetiva (CTCe) da fração argila livre de matéria orgânica (argila- $\mathrm{NaOCl).}$ 
Embora os óxidos de Fe livres normalmente apresentem elevada ASE (Borggaard, 1983; Sambatti et al., 2002), para a maioria dos solos, sua remoção promoveu considerável incremento (em média, $33 \%$ ) na ASEe, em comparação aos valores obtidos para a fração argila-natural. No entanto, isso não ocorreu para o Chernossolo Ebânico, de Bagé-RS (perfil 8, ME1), o qual apresenta menos de $1 \%$ de óxidos de $\mathrm{Fe}$ livres; do total, 57 \% eram extraíveis com solução de OAA (Quadro 2). Esse fato pode ser explicado pela eliminação do efeito de agregação e recobrimento das partículas promovido pela matéria orgânica e pelos óxidos de $\mathrm{Fe}$ em consideráveis proporções nos solos estudados.

Rolim Neto et al. (2004) observaram diminuição da ASEe após remoção dos óxidos de Fe, numa intensidade maior em Cambissolos, comparados com os Latossolos formados a partir de rochas vulcânicas básicas e ultrabásicas.

A presença dos óxidos de Fe dificulta ou impede o completo recobrimento da superfície da amostra pelo $\mathrm{N}_{2}$ (Kahle et al., 2002; Kaiser \& Guggenberger, 2003). Em contrapartida, a remoção dos óxidos de Fe livres fez com que a adsorção do EGME ocorresse na superfície que efetivamente corresponde à CTCe. Dessa forma, constatou-se elevada, positiva e significativa relação entre a CTCe e a ASEt $\left(R^{2}=0,81\right)$ e a ASEi $\left(R^{2}=0,88\right)$.

Em todas as amostras, a remoção dos óxidos de $\mathrm{Fe}$ livres promoveu diminuição na CTCe. Comportamento semelhante foi obtido por Kahle et al. (2002), que encontraram correlação positiva entre o teor de $\mathrm{Fe}$ extraído com DCB e a adsorção de C orgânico em amostras padrão de solo e de argilominerais, utilizadas em estudos mineralógicos.

\section{CTCe e ASE da fração argila livre de matéria orgânica, dos óxidos de ferro livres, da caulinita e da gibbsita, argila-NaOCl + DCB + NaOH $5 \mathrm{~mol} \mathrm{~L}^{-1}$}

Os minerais concentrados pelos métodos de dissolução seletiva empregados são constituídos principalmente por argilominerais do tipo 2:1 (Figura 1b). Esses minerais caracterizam-se por apresentar alta atividade, representada pelos elevados valores de CTCe - em média, $1.054 \mathrm{mmol}_{\mathrm{c}} \mathrm{kg}^{-1}$.

Entre a ASEe e a CTCe observou-se relação positiva, porém com baixo coeficiente de determinação $\left(\mathrm{R}^{2}=0,33\right)$, próximo àquele obtido para as frações argila- $\mathrm{NaOCl}$ e argila- $\mathrm{NaOCl}+\mathrm{DCB}$, o que se deve às variações impostas pelas condições pedogenéticas de formação dos solos. A elevada ASEe encontrada deve-se, provavelmente, ao menor tamanho de partícula dos argilominerais do tipo 2:1 (Borchardt, 1989), concentrados pelos métodos de dissolução seletiva empregados, uma vez que $o \mathrm{~N}_{2}$ não recobre a superfície interna dos minerais.
A alta densidade de cargas nessa fração, aliada à elevada ASE, é mais bem representada pela relação entre a ASEt e a CTCe $\left(R^{2}=0,51\right)$. O valor médio de ASEt foi de $201,61 \mathrm{~m}^{2} \mathrm{~g}^{-1}$; a ASEi contribui com aproximadamente $60 \%$ da ASEt. Os elevados valores de CTCe e de ASEt encontrados revelam a presença desses minerais mais ativos, condizentes com os da literatura (Borchardt, 1989; Schwertmann \& Herbillon, 1992).

Entre a CTCe e ASEi observou-se baixa relação $\left(\mathrm{R}^{2}=0,23\right)$, mas estatisticamente significativa (Quadro 3). Nesse caso, embora os métodos de dissolução química empregados tenham sido eficientes para concentrar os argilominerais do tipo 2:1, responsáveis pela ASEi, parte desses minerais pode ter sido dissolvida juntamente com a caulinita e a gibbsita.

\section{Contribuição dos minerais na fração argila aos valores de ASE dos solos estudados}

Para a fração argila-natural, nenhuma das espécies minerais avaliadas correlacionou-se significativamente com os valores de ASE (Quadro 4). Com a remoção da matéria orgânica, correlações positivas e significativas foram encontradas entre os valores Fed com a ASE (interna, total e externa). A caulinita apresentou correlações significativas e negativas com todos os valores de ASE da fração argila-NaOCl e também para a ASEi e ASEt da fração argila- $\mathrm{NaOCl}+\mathrm{DCB}$, ao passo que a gibbsita não mostrou correlação com ASE em nenhum dos tratamentos de dissolução seletiva.

Quadro 4. Coeficientes de correlação de Pearson (r) entre a componente da fração argila dos solos e a área superficial específica (ASE) após os tratamentos de dissolução seletiva

\begin{tabular}{|c|c|c|c|c|}
\hline ASE & Fed & Cau & Gib & $2: 1$ \\
\hline \multicolumn{5}{|c|}{ Argila-natural } \\
\hline Externa: BET & $\mathrm{ns}$ & $\mathrm{ns}$ & $\mathrm{ns}$ & $\mathrm{ns}$ \\
\hline Interna: ASEt-ASEe & $\mathrm{ns}$ & $\mathrm{ns}$ & $\mathrm{ns}$ & $\mathrm{ns}$ \\
\hline Total: EGME & $\mathrm{ns}$ & $\mathrm{ns}$ & ns & ns \\
\hline \multicolumn{5}{|c|}{ Argila-NaOCl } \\
\hline Externa: BET & $0,40 *$ & $-0,51 * *$ & $\mathrm{~ns}$ & $0,73 * * *$ \\
\hline Interna: ASEt-ASEe & $0,66 * * *$ & $-0,56 * *$ & $\mathrm{~ns}$ & $0,80 * * *$ \\
\hline Total: EGME & $0,67 * * *$ & $-0,51 * *$ & $\mathrm{~ns}$ & $0,73 * * *$ \\
\hline \multicolumn{5}{|c|}{ Argila- $\mathrm{NaOCl}+\mathrm{DCB}$} \\
\hline Externa: BET & - & $\mathrm{ns}$ & $\mathrm{ns}$ & $\mathrm{ns}$ \\
\hline Interna: ASEt-ASEe & - & $-0,65^{* * *}$ & $\mathrm{~ns}$ & $0,75^{* * *}$ \\
\hline Total: EGME & - & $-0,53 * *$ & $\mathrm{~ns}$ & $0,68 * * *$ \\
\hline
\end{tabular}

Fed: teor de ferro extraível com DCB; Cau: caulinita; Gib: gibbsita; $2: 1=$ residual. ***, **, * e ns: Significativos a $0,1,1 \mathrm{e}$ $5 \%$ e não-significativo a $5 \%$, respectivamente. 
Os maiores coeficientes de correlação positivos e estatisticamente significativos $(p<0,001)$ foram encontrados para os argilominerais do tipo 2:1, confirmando a efetiva contribuição desses minerais aos valores de ASE, principalmente para a ASEi, presente unicamente nesses minerais.

\section{CONCLUSÕES}

1. A caulinita é o mineral predominante na fração argila dos solos com drenagem variando de moderada a excessiva, seguida dos minerais de argila expansivos do tipo 2:1 ou dos óxi-hidróxidos de $\mathrm{Fe}$ e Al. A proporção decrescente dos argilominerais do tipo 2:1 e crescente de gibbsita está de acordo com o aumento da condição de drenagem dos solos.

2. Os valores de ASEe não se correlacionam com os valores de CTCe da fração argila-natural: elevada ASEe não implica elevada CTCe.

3. A remoção da matéria orgânica é de fundamental importância para determinação da ASEe pelo método BET- $\mathrm{N}_{2}$.

4. Os argilominerais do tipo 2:1 concentrados pelos métodos de dissolução seletiva são os principais responsáveis pela CTCe e pela ASEt e apresentaram valores médios de $1.054 \mathrm{mmol}_{\mathrm{c}} \mathrm{kg}^{-1} \mathrm{e} 202 \mathrm{~m}^{2} \mathrm{~g}^{-1}$, respectivamente.

5. A ASEi é o melhor atributo relacionado à CTC, sendo responsável por aproximadamente $60 \%$ da ASEt da fração argila desferrificada e concentrada em argilominerais do tipo 2:1.

6. Para amostras livres de matéria orgânica e com baixos teores de minerais expansíveis do tipo 2:1, os valores de ASEe e ASEt tendem a ser próximos.

\section{LITERATURA CITADA}

BARNHISEL, R.I. \& BERTSCH, P.M. Chlorites and hydroxyinterlayered vermiculite and smectite. In: DIXON, J.B. \& WEED, S.B., eds. Minerals in soil environments. 2.ed. Madison, Soil Science Society of America, 1989. p.729-788.

BORCHARDT, G. Smectites. In: DIXON, J.B. \& WEED, S.B., eds. Minerals in soil environments. 2.ed. Madison, Soil Science Society of America, 1989. p.675-727.

BORGGAARD, O.K. Effect of surface area and mineralogical of iron oxides on their surface charge and anionadsorption properties. Clays Clay Miner., 31:230-232, 1983.

BRUNAUER, S.; EMMETT, P.H. \& TELLER, E. Adsorption of gases in multimolecular layers. J. Am. Chem. Soc., 60:309319, 1938.

CAMARGO, O.A.; MONIZ, A.C.; JORGE, J.A. \& VALADARES, J.M.A.S. Métodos de análise química, mineralógica e física de solos do Instituto Agronômico de Campinas. Campinas, 1986. 94 p. (Boletim Técnico, 106)
CARTER, D.L.; MORTLAND, M.M. \& KEMPER, W.D. Specific surface. In: KLUTE, A., ed. Methods of soil analysis: Physical and mineralogical methods. 2.ed. Madison, Soil Science Society of America, 1986. Part 1. p.413-423.

CHIOU, C.T.; LEE, J.F. \& BOYD, S.A. The surface area of soil organic matter. Environ. Sci. Technol., 24:1164-1166, 1990.

CHURCHMAN, G.J. \& BURKE, C.M. Properties of subsoil in relation to various measures of surface area and water content. J. Soil Sci., 42:463-478, 1991.

COSTA, A.C.S.; BIGHAM, J.M. \& TRAINA, S.J. Minerology of Oxisols after application of sequential dissolution procedure. In: VM GOLDSCHMIDT CONFERENCE, 1995, Happy Valley. Proceedings. Happy Valley, Geochemical Society, 1995. v.1. p.39

COSTA, A.C.S.; BIGHAM, J.M.; RHOTON, F.E. \& TRAINA, S.J. Quantification and characterization of maghemite in soils derived from volcanic rocks in Southern Brazil. Clays Clay Miner., 47:466-473, 1999.

COSTA, A.C.S.; BIGHAM, J.M.; TORMENA, C.A. \& PINTRO, J.C. Clay mineralogy and cation exchange capacity of Brazilian soils from water contents determined by thermal analysis. Therm. Acta, 413:73-79, 2004.

CURTIN, D. \& SMILLIE, G.W. Estimation of components of soil cation exchange capacity from measurements of specific surface and organic matter. Soil Sci. Soc. Am. J., 40:461-462, 1976.

DIXON, J.B. Kaolin and serpentine group minerals. In: DIXON, J.B. \& WEED, S.B., eds. Minerals in soil environments. 2.ed. Madison, Soil Science Society of America, 1989. p.467-525.

EMPRESA BRASILEIRA DE PESQUISA AGROPECUÁRIA EMBRAPA. Centro Nacional de Pesquisa de Solos. Sistema brasileiro de classificação de solos. Rio de Janeiro, 1999. 412p.

EMPRESA BRASILEIRA DE PESQUISA AGROPECUÁRIA EMBRAPA. Serviço Nacional de Levantamento e Conservação de Solos. Manual de métodos e análises de solos. 2.ed. Rio de Janeiro, 1997. 212p.

FONTES, M.P.F. Vermiculita ou esmectita com hidroxi nas entrecamadas: Proposição de nomenclatura. R. Bras. Ci. Solo, 15:24-28, 1990.

FONTES, M.P.F.; CAMARGO, O.A. \& SPOSITO, G. Eletroquímica das partículas coloidais e sua relação com a mineralogia de solos altamente intemperizados. Sci. Agríc., 58:627-646, 2001.

GROHMANN, F. Correlação entre superfície específica e outras propriedades de solos de São Paulo. R. Bras. Ci. Solo, 1:9-12, 1977.

JAYNES, W.F \& BIGHAM, J.M. Multiple cation-exchange capacity measurements on standard clays using a commercial mechanical extractor. Clays Clay Miner., 34:93-98, 1986.

KAHLE, M.; KLEBER, M. \& JAHN, R. Predicting carbon content in illitic clay fractions from surface area, cation exchange capacity and dithionite-extractable iron. Eur. J. Soil Sci., 53:639-644, 2002. 
KAHLE, M.; KLEBER, M. \& JAHN, R. Retention of dissolved organic matter by phyllosilicate and soil clay fractions in relation to mineral properties. Organic Geochem., 35:269$276,2004$.

KAISER, K. \& GUGGENBERGER, G. Mineral surfaces and soil organic matter. Eur. J. Soil Sci., 54:219-236, 2003.

KÄMPF，N. \& SCHWERTMANN，U. The 5M-NaOH concentration treatment for iron oxides in soils. Clays Clay Miner., 30:401-408, 1982.

KÄMPF, N.; AZEVEDO, A.C. \& COSTA Jr., M.I. Estrutura básica de argilominerais 2:1 com hidróxi-Al entrecamadas em Latossolo Bruno do Rio Grande do Sul. R. Bras. Ci. Solo, 19:185-190, 1995.

KARATHANASIS, A.D. \& HARRIS, W.G. Quantitative thermal analysis of soil materials. In: AMONETTE, J.E. \& ZELAZNY, L.W., eds. Quantitative methods in soil mineralogy. Madison, Soil Science Society of America, 1994. p.360-408.

MAYER, L.M. \& XING, B. Organic matter-surface area relationships in acid soils. Soil Sci. Soc. Am. J., 65:250$258,2001$.

MEHRA, O.P. \& JACKSON, M.L. Iron oxide removal from soils and clay by a dithionite-citrate system buffered with sodium bicarbonate. Clays Clay Miner., 7:317-327, 1960.

MONIZ, A.C.; BUOL, S.W. \& WEED, S.B. Formation of an Oxisol-Ultisol transition in São Paulo, Brazil: II. Lateral dynamics of chemical weathering. Soil Sci. Soc. Am. J., 46:1234-1239, 1982.

MOORE, D.M. \& REYNOLDS Jr, R.C. X-ray diffraction and the identification and analysis of clay minerals. 2.ed. New York, Oxford University Press, 1997. 378p.
PENNELL, K.D.; BOYD, S.A. \& ABRIOLA, L.M. Surface area of soil organic matter reexamined. Soil Sci. Soc. Am. J., 59:1012-1018, 1995.

PERROT, K.W. Freeze-drying of soil clays. Geoderma, 17:219$224,1977$.

PETERSEN, L.W.; MOLDRUP, P.; JACOBSEN, O.H. \& ROLSTON, D.E. Relations between specific surface area and soil physical and chemical properties. Soil Sci., 161:921, 1996.

ROLIM NETO, F.C.; SCHAEFER, C.E.G.R.; COSTA, L.M.; CORREAA, M.M.; FERNANDES FILHO, E.I. \& IBRAIMO, M.M. Adsorção de fósforo, superfície específica e atributos mineralógicos em solos desenvolvidos de rochas vulcânicas do Alto Paranaíba (MG). R. Bras. Ci. Solo, 28:953-964, 2004.

SAMBATTI, J.A.; COSTA, A.C.S.; MUNIZ, A.S.; SENGIK, E.; SOUZA JUNIOR, I.G. \& BIGHAM, J.M. Relações entre a substituição isomórfica de $\mathrm{Fe}$ por $\mathrm{Al}$ e as características químicas e mineralógicas de hematitas sintéticas. R. Bras. Ci. Solo, 26:117-124, 2002.

SAS INSTITUTE. Procedure guide for personal computers. 5.ed. Cary, 1999. 334p.

SCHWERTMANN, U. \& HERBILLON, A.J. Some aspects of fertility associated with the mineralogy of highly weathered tropical soils. In: LAL, R. \& SANCHEZ, P., eds. Myths and science of soils of the tropics. Madison, Soil Science Society America, 1992. p.47-59. (Special Publication, 29)

TILLER, K.G. \& SMITH, L.H. Limitations of EGME retention to estimate the surface area of soils. Aust. J. Soil Res., 28:1-26, 1990 